\title{
First-mover Strategy and Performance of Late Movers among MNEs in an Emerging Market
}

\author{
Wanxing Jiang ${ }^{1 *}, \mathrm{Ji} \mathrm{Li}^{1}$, Tao $\mathrm{Liu}^{2}$ and Xiaolong $\mathrm{Tao}^{3}$ \\ ${ }^{1}$ Department of Management, Hong Kong Baptist University, Hong Kong \\ ${ }^{2}$ College of Economics and Management, Southwest University, China \\ ${ }^{3}$ School of Business Administration and Tourism Management, Yunnan University, China \\ Email: wanxing.jiang@gmail.com
}

\begin{abstract}
Research shows several effects of first-mover strategy on first movers' performance. However, the effects of first-mover strategy on late movers' performance have not been sufficiently studied. Integrating viewpoints from theories of organizational sociology as well as those of business strategy, we predict that the first-mover strategy should have both direct and indirect effects on the performances of later movers. Moreover, the effects are more likely to be significant in emerging markets with more environmental uncertainties. To test these predictions, we develop hypotheses and test them empirically among MNEs in China's insurance industry. This test shows that, other things being equal, first-mover strategy does cause significantly more imitation among late movers. The imitation, in turn, has significant effects on other dimensions of firm performance, including less deviation from the industry norm and better financial performance. Finally, in the process of imitation, similarity in home-country culture also has a significant and positive effect.
\end{abstract}

Keywords: First-mover strategy; late movers; MNEs; emerging market

\section{Introduction}

This research tests the effect of first-mover strategy on the performance or behavior of late movers, such as late movers' performance in terms of market diversification, deviation from industry norm, labor productivity and financial performance. In spite of the studies on the effects of first-mover strategy (Lieberman and Montgomery, 1988; Patterson, 1993; Kunkel, 1991; Haunschild and Miner, 1997; Lieberman and Asaba, 2006), it remains unclear how the first-mover strategy may affect the performance of the late movers, such as the performances associated with the imitation of first movers. Moreover, it remains unclear how institutional factors, such as firms' home-country culture, may influence the imitation process. Several related questions can also be asked. For instance, should the first-mover strategy attract more imitation than the late mover strategy? Are firms that imitate first movers less likely to deviate from industry norm for a certain strategy, such as diversification? Finally, should the first-mover strategy also have some indirect effects on the performances of late movers, such as their financial performance after imitating the first movers?

Focusing on the multi-national enterprises (MNEs) in China's insurance industry, our current paper addresses these issues, as mentioned above. As we are discussing later in this paper, some of the MNEs entered China in early 1990s as first movers, while the majority of MNEs entered China much later as late movers. After establishing in one geographic market, such as Beijing, these MNEs may have market diversification, which includes product diversification and geographic market diversification. In this process, should the first-mover strategy have any effects on their market diversification performance? Our current research studies this issue from a perspective of inter-organizational imitation.

Studying the imitation and related issues should be of interest because it may help to facilitate a better understanding of the consequences of first-mover strategy, especially those in emerging economies where there are more environmental uncertainties. The study can also increase our knowledge about the relationships among inter-organizational imitation, deviation from industry norms and institutional/cultural factors. To date, our knowledge on these relationships has been limited. In addition, studying these issues can also help practitioners in formulating and implementing business strategy. With a better understanding on how first-mover strategy may influence the performance of late 
movers, both the first movers and the late movers can predict the consequences of first-mover strategy better, avoid potential mistakes earlier, and identify more business opportunities. Take the late movers as an example. When entering an emerging economy, they should make an important decision whether to imitate the first movers on such an issue as market diversification. With a better understanding of the consequences of the imitation, it would be easier for managerial practitioners to make such a decision.

In the rest of this paper, an empirical study testing the issues will be reported first before providing a detailed discussion of this study, we first review the relevant literature, based on which we develop a theoretical model with testable hypotheses. After that, research methodology will be discussed, followed by a report of the data analysis result.

\section{Theoretical Background and Predictions}

\subsection{First-Mover Strategy and the Imitation by Late Movers}

In the business strategy literature, a first mover can be defined as an organization which is the first to employ a particular strategy within a context of specified scope. The strategy of this first mover, i.e., first-mover strategy, can be related to a service strategy, a process strategy or a product strategy; and the scope can be a market segment, an industrial sector or a foreign country (Patterson, 1993). In the current study, we adopt this definition because of its generality and strategic focus.

It has been argued that first-mover strategy has several positive effects on the performances of the first movers themselves (Chaffee, 1985; Urban, Carter, Gaskin and Mucha, 1986; Robinson and Fornell, 1985; Kunkel, 1991; Patterson, 1993). For instance, in terms of brand loyalty, pioneering brands possess demand advantages over following brands because consumer preference rests with the first brand tried that performs adequately (Schmalensee, 1982). In terms of organizational learning, first movers are more likely than their followers to have more extensive learning and thus have better access to opportunities (Glazer, 1985). First movers can often initiate the build-up of experiential raw material so that they develop the most advanced insights, associations and causal maps within a specified context (Patterson, 1993). In terms of the generic strategies proposed by Porter (1985), being a first mover may also lead to several advantages: establishing a uniqueness in the market, engaging in price skimming, pre-emptying a product or market positioning, using switching costs to lock up sales, setting up exclusive distribution channels, defining the standards for new technology, securing patents or government-conferred status, and controlling other scarce resources critical for success in competitions (Patterson, 1993). They are more likely to increase profitability as the consequence of early market entry (Frynas, Mellahi, and Pigman, 2006). Finally, from the perspective of population ecology, market pioneers may outperform early followers or later entrants to the extent that they all pursue a generalist strategy (Lambkin, 1988).

In spite of the research, it remains unclear the effects of first-mover strategy on the performance of late movers. For instance, it is not clear how first-mover strategy may affect the market diversification performance of late-movers in an emerging economy.

This research paper addresses the research gap, as discussed above. According to research (Baum, Li and Usher, 2000), it is predictable that the first-mover strategy may lead to imitation by late movers, including the imitation in term of market diversification strategy. The main reason for this is the effect of vicarious learning, which refers to a learning process in which organizations adopt or avoid certain actions based on their perceived impact (Cyert and March, 1963). First movers are argued to be more likely than late movers to be perceived as a source of superior information (Lieberman and Asaba, 2006). Even if there is no hard evidence that a first mover is really successful, the mere fact that a first mover has successful established itself in an emerging market may create a perception of success among late movers. With the perception, the late movers are likely to imitate the strategy and practice of the first mover because the imitation may involve lower risk or a higher likelihood of success.

It should be pointed out that at the early stage of the imitation process, the number of firms involved can be very small so that institutional isomorphism may not take place. However, regardless of how small the number is, the imitation may still occur. The main reason for this is that firms prefer to learn from those with salient performance (Haunschild and Miner, 1997). For instance, when MNEs have just entered an emerging market with many environmental uncertainties, they may find it hard to find relevant firms with salient or successful performance other than those first movers that have already 
established themselves. As a result, these first movers may attract the attention of late movers and become the target of imitation (Baum, Li and Usher, 2000). In this scenario, the mere fact that a first mover has established successfully in the market can be sufficient to prompt imitation by the late movers. Accordingly, we propose:

Hypothesis 1 (H1). Other conditions being equal, first-mover strategy can have a significant and positive effect on the imitation behaviors of late movers in the same industry, and this is especially true for late movers in an emerging economy.

\subsection{The Effect of Home-country Culture}

Home-country culture, as an institutional factor, can also influence the imitation of late movers, and this can be especially true for MNEs in an emerging economy such as China. Here the home-country culture first influences the similarity in culture between the first movers and the late movers. With a high level of cultural similarity, the late movers should be more likely to imitate the first movers.

Theoretically, the moderating effect here can be explained by social network theory (Granovetter, 1985; Gulati, Nohria and Zaheer, 2000) as well as institutional theory. According to social network theory, organizations are linked by their network ties. As a result, they are more likely to gain more detailed information about each other through their networks, which should facilitate interorganizational imitation (Lieberman and Asaba, 2006). Accordingly, it is arguable that MNEs from the same or similar cultures are more likely to imitate each other because they are likely to have more network ties with each other than with those from different cultures. Moreover, according to research on inter-organizational imitation, firms are indeed more likely to imitate those that are similar (Haunschild and Miner, 1997), which should include cultural similarity. Based on these observations, it is arguable that MNEs from the same or similar cultures are more likely to imitate each other because of their cultural similarities.

In addition, the moderating effect can also be explained by institutional theory. Institutional theory posits that institutional elements, including cognitive and cultural elements such as societal culture, influence the interpretation of issues or actions as they emerge and persist (Scott, 2001). Accordingly, firms with similar institutions, such as similar home-country cultures, are more likely to explain their internal and external environments similarly, as a result of which they are more likely to formulate and implement similar strategies than are firms that have great cultural differences. Consistent with this, given the information that a certain first mover has adopted a market diversification strategy, firms that share similar cultures are more likely to make a similar decision. Accordingly, we propose:

Hypothesis 2 (H2). Among MNEs of the same industry, the late movers are more likely to imitate the first movers given a high level of similarity in home-country culture.

\subsection{Indirect Effects of First-mover Strategy on the Performance of Late Movers}

Through influencing the imitation of late movers, first-mover strategy may also influence the performance of late movers indirectly. First, it may influence the deviation from the industry norms, such as the norms about market diversification strategy. In other words, the imitation by the late movers can influence their deviation from their industry norms. Specifically, with many late movers imitating the strategy of a first mover, the imitation itself may become institutionalized. As a result, the more firms imitate first movers, the more likely they shape a local industry norm consistent with their imitation.

Integrating the viewpoints of institutional theory and the theory of inter-organizational imitation, as discussed above, we can propose hypotheses regarding the effects of imitation on industry norms and firm performance. First, it is arguable that an industry norm related to a strategic action, such as that related to a market diversification strategy, is likely to be consistent with the strategic actions of the first movers than with those of the late movers. The reason for this is that if firms are more likely to imitate the strategy of first movers rather than that of late movers, the strategy of first movers will be more consistent with the relevant industry norm. Accordingly, we propose the following hypotheses:

Hypothesis 3a (H3a). There will be less deviation from the industry norm among MNEs that imitate the first movers than among those that imitate late movers. 
Hypothesis 3b (H3b). There will be less deviation from the industry norm among MNEs that imitate the first movers than among those that do not.

Second, the deviation of the norm may influence other performance of the late movers. According to institutional theory, for a given group of organizations, deviation from group norms - in any direction can yield inferior performance (DiMaggio and Powell, 1983). Other research has shown that deviations from an institutionalized or commonly-adopted competitive behavior can influence firm performance negatively (Chen and Hambrick, 1995). In other words, consistent with the logic of institutional theory, research evidence suggests that firms' competitive behavior, including their market diversification strategies (including product market entry and geographic market entry), should match the related industry norm. If not, firm performance can be negatively affected.

According to all these, as discussed above, we hypothesize that the deviation can negatively affect firms' labor productivity and profitability. As firms that imitate first movers are likely to deviate from industry norms to a lesser extent than those that imitate late movers or those that do not imitate, we predict that firms which imitate the first movers should have better performances:

Hypothesis 4a (H4a). With imitation of first mover resulting in less deviation from the industry norm, there will be a positive relationship between the imitation and labor productivity among firms.

Hypothesis 4b (H4b). With imitation of first mover resulting in less deviation from the industry norm, there will be a positive relationship between the imitation and profitability (ROA) among firms.

\section{Methods}

\subsection{Setting, Sample, and Data}

To test our hypotheses, we selected all foreign insurance firms in a major emerging market, the People's Republic of China. These firms include both wholly-owned and joint ventured entities. The performance data for these firms were mainly drawn from two sources: 1) the firms' websites and six other independent websites focusing on the activities of and data on insurance firms in China; and 2) the Yearbook of China's Insurance Industry, an annual publication issued by the Insurance Association of China that records information on all domestic and overseas insurance firms operating in the country. Each firm provides information about itself for the Yearbook. An independent editorial board, which consists of representatives from all the firms and officials from China's Statistical Bureau, is responsible for the validity and credibility of the data.

Our sample actually represents the entire population of foreign-invested insurance firms in China during that period. The first foreign insurer, AIA (China), entered China in 1992 as an entity wholly owned by its parent firm from the United States. Subsequently, other MNEs in the insurance industry, such as firms from European countries and Japan, also entered China. For example, in 1999, just before it formally joined the World Trade Organization (WTO), China granted operating licenses to four more overseas insurers (Wang, 1999).

The majority of foreign insurance firms entered China after the country signed the WTO treaty in 2000. According to this treaty, China was required to open up its insurance markets step by step to all foreign insurance firms by 2004. Accordingly, we have focused on firms' imitation and their multimarket contact after the year 2004. This approach is based on the rationale that firms' market diversification plans should not have been subject to significant limitations or intervention by the Chinese government after 2004. If that were not the case, any firm or its home country government was able to take a case to the WTO, which would have been reported by the news media. We conducted library research to check on whether any such cases were brought, but failed to find any. Accordingly, we conclude that the market diversification plans of firms in China did not suffer from any significant intervention by the host-country government after 2004.

\subsection{Measurement}

\subsubsection{Independent Variables}

The main independent variable in this study is imitation. In this paper, we focus on the imitation of market diversification because it is more feasible given our data. This approach has actually been 
adopted by several prior research that measured imitation (Haunschild and Miner, 1997). Following the research, we measured this variable by testing whether a follower adopted a diversification strategy that a first or late mover had already implemented. To measure how the firms in our sample imitated market diversification strategies adopted by first movers or later movers, we first defined the first movers as those that entered the Chinese market before China joined the WTO in 2000. Given that these firms successfully established themselves in the Chinese market before China signed the WTO treaty, we assumed that they would be perceived as successful first movers by many late movers. Consistent with this approach, we defined later movers as those that entered China during the period 2000-2001 after China had signed the WTO treaty ${ }^{1}$. Based on these definitions, we created a measure of first mover with first movers assigned a value of one and later movers assigned a value of zero.

In addition, based on the definition of first mover, we developed an index of imitation to measure how the followers, i.e., firms that entered China after 2001, imitated the diversification strategies adopted by the first movers, i.e.

$$
I M I=\sum_{i=1}^{2}\left[\left\{\left(F H_{i}\right)_{T}-\left(F H_{i}\right)_{T-1}\right\} *\left\{\left(I H_{i}\right)_{T+1}-\left(I H_{i}\right)_{T}\right\}\right]
$$

$\mathrm{H}_{1}$ : product market diversification

$\mathrm{H}_{2}$ : geographic market diversification

In this index, $T$ represents a given year in which a firm was operating in China. $T+1$ and $T-1$ are the year after and year before $T . F H_{i}$ represents the product market entry or geographic market entry of a first mover in a given year as measured by the entropy formula, the method most commonly adopted by researchers to measure firms' diversification strategies through market or product diversification (cf. Hitt, Hoskisson and Kim, 1997), i.e.,

$$
F H_{\mathrm{i}}=\sum\left(p_{i k} \times \ln _{k=1}^{n}\left(1 / p_{i k}\right)\right)
$$

where $\mathrm{p}_{\mathrm{ik}}$ is the percentage of premiums collected by firm $i$ in the $k^{\text {th }}$ market (a product market or geographic market).

With the same approach, we also measured how the late movers imitated the late movers in terms of market diversification:

$$
I M I=\sum_{i=1}^{2}\left[\left\{\left(L H_{i}\right)_{T}-\left(L H_{i}\right)_{T-1}\right\} *\left\{\left(I H_{i}\right)_{T+1}-\left(I H_{i}\right)_{T}\right\}\right]
$$

$\mathrm{H}_{1}$ : product market diversification index

$\mathrm{H}_{2}$ : geographic market diversification index

It should also be noted that this IMI index distinguishes the imitation of a market diversification strategy from simple copy of every specific action or expansion adopted by one of the first or late movers. For instance, when the IMI index between a follower and a first mover is positive, it does not mean that the follower copies specific actions led by the first mover to enter the product or geographic markets which the first mover has just entered. Instead, when the follower expands its product or geographic market portfolio in line with diversification strategy taken by the first mover or a late mover in the previous year, we consider this to be a case of imitation related to market diversification. As a result, the value of IMI will be positive. If the follower does not do so, the value of IMI will be zero or negative.

In addition, we measured the firms' home-country cultural similarity with a dummy. If both firms in a given dyad were from the same or similar cultures, such as where they were both from Western countries or both from East Asian economies, we code the dummy as one for the dyad. Otherwise, we coded the dummy as zero.

Finally, to test hypotheses $3 \mathrm{a}$ and $3 \mathrm{~b}$, we measured imitation of a first mover rather than a late mover with a dummy. If a given firm imitated a first mover rather than a late mover, we coded the dummy as one. Alternatively, if a given firm imitated a late mover rather than a first mover, we coded the dummy as zero. Using the same approach, we also measured whether imitation of the first mover occurred or not, with one representing imitation and zero representing non-imitation.

${ }^{1}$ Because China officially acceded to the WTO on 11 December 2001, it is better to refer to the signing time of the WTO treaty here. 


\subsubsection{Dependent Variables}

The main dependent variable here is deviation from the industry norm. We measured this variable following the method developed by Chen and Hambrick (1995). Specifically, we took the mean of all firms' diversifications as industry norms. A firm's deviation from the industry norm was then calculated as the sum value (both product market entry and geographic market entry) of the absolute distances between its own level of diversifications and the relevant industry norms.

Finally, we measured two dimensions of firm performance. One is a firm's labor productivity, which was computed as the firm's total sales (premium income) over its total number of employees. The other dimension was the firm's return on assets (ROA).

\subsubsection{Control Variables}

We controlled for the effect of year because the relationship between firm strategy and the dependent variable of firm performance might be moderated by the nature of the business environment in a given year (Li, Lam, Sun \& Liu, 2008). We also controlled for the effect of location to take into account the level of economic development in each of China's local markets. According to prior research, economic development should influence market capability, which in term could influence the motivation of a given market to diversify. In addition, we controlled for the effect of firm size because large firms might have a higher level of diversification. This variable was tested by the natural log of the total employee number. Finally, we controlled for the effect of product focus among firms in our sample. Some firms had focused on property insurance products, while others had concentrated on life insurance products. Based on the information used for product focus, which was taken from the Yearbook, we created a product focus measure to measure the similarity of the firms in terms of product focus. If the firm focused on property insurance products, we coded this variable as one. Otherwise, we coded it as zero.

\section{Data Analysis and Results}

Table 1 presents the descriptive statistics for our data. Some interesting correlations can be observed among the variables. For instance, locations with a high level of economic development in China actually have a negative relationship with firm profitability, as measured by ROA. This result can be explained by the fact that most of our sample firms have been competing in China's coastal cities with a higher level of economic development. To increase their market shares in these markets, the firms are more willing to cut their prices or increase their promotion spending in these coastal markets. As a result, their short-term profitability can be poorer than that of firms operating in less-developed inland Chinese cities.

Table 1. Descriptive statistics $(\mathrm{N}=1036)$

\begin{tabular}{l|l|l|l|l|l|l|l|l|l|l|l|l}
\hline VARIABES & M. & S.D. & 1 & 2 & 3 & & 4 & & 6 & 9 & 10 & 11 \\
\hline 1. Year & 2005.482 & 0.499 & 1 & & & & & & & & & \\
\hline 2. Location & 0.582 & 0.492 & -0.021 & 1 & & & & & & & & \\
\hline 3. Product Focus & 0.614 & 0.489 & 0.012 & -0.011 & 1 & & & & & & & \\
\hline 4. Firm Size & 2.77 & 0.88 & -0.011 & 0.04 & 0.021 & 1 & & & & & & \\
\hline 5. First-mover Strategy & 0.121 & 0.185 & 0.031 & 0.043 & 0.032 & $0.109^{*}$ & 1 & & & & & \\
\hline $\begin{array}{l}\text { 6. Product } \\
\text { Diversification }\end{array}$ & 1.072 & 0.213 & -0.036 & -0.006 & -0.262 & $0.112^{*}$ & -0.121 & 1 & & & & \\
\hline $\begin{array}{l}\text { 7. Market } \\
\text { Diversification }\end{array}$ & 0.997 & 0.194 & $0.243^{* *}$ & 0.018 & -0.054 & $0.119^{*}$ & 0.014 & -0.009 & 1 & & & \\
\hline 8. Similarity in Culture & 0.512 & 0.533 & 0.009 & -0.006 & $0.271^{* *}$ & 0.031 & 0.033 & $-0.107^{*}$ & 0.043 & 1 & & \\
\hline 9. Labor Productivity & 0.621 & 0.603 & 0.071 & 0.065 & -0.089 & 0.033 & 0.025 & $-0.133^{*}$ & $-0.201^{*}$ & $-0.235^{*}$ & 1 & \\
\hline $\begin{array}{l}\text { 10. Return on Assets } \\
\text { ROA) }\end{array}$ & 0.013 & 0.032 & $0.193^{*}$ & $-0.169^{*}$ & $-0.113^{*}$ & 0.051 & -0.007 & -0.004 & $-0.191^{*}$ & $0.165^{*}$ & $0.946^{* * *}$ & 1 \\
\hline
\end{tabular}

Note: ${ }^{*} \mathrm{p}<0.05 ;{ }^{* *} \mathrm{p}<0.01 ;{ }^{* * *} \mathrm{p}<0.001$. 
Table 2. Imitating first movers or later movers among all imitations?

\begin{tabular}{c|c|c}
\hline Variable & Model 1 & Model 2 \\
\hline Year & 0.018 & 0.001 \\
& $(0.121)$ & $(0.122)$ \\
\hline Location & 19.967 & 19.938 \\
& $(5.016)$ & $(4.943)$ \\
\hline Product focus & $0.275^{*}$ & $0.246^{*}$ \\
\hline Firm size & $(0.125)$ & $(0.127)$ \\
\hline Constant & $0.252^{*}$ & $0.244^{*}$ \\
\hline Than later Movers & $(0.133)$ & $(0.136)$ \\
\hline H1: Imitating First Movers Rather & -58.954 & -40.749 \\
Note: $p$ p $<.05 ; *$ p < 0.01; *** p $<0.001$. & $(7.878)$ & $(7.949)$ \\
\hline
\end{tabular}

To test the hypotheses proposed above, we first conducted logistic regression analyses. Specifically, we tested the tendency of late movers to imitate first movers (i.e. hypothesis 1). Imitation, which is coded as one when imitation is positive and as zero otherwise, is entered as the dependent variable. We subsequently entered the four control variables, i.e., year, location, product focus and firm size (Model 1). We then added the measure for first mover, the independent variable (Model 2). Table 2 shows the results of this analysis, which supports hypothesis 1 . Specifically, among all the positive imitations by the followers, the first mover effect is positive and significant $(\mathrm{p}<0.001)$.

Logistic regression analysis was conducted to test hypothesis 3 proposed above. In this analysis, we entered imitation of first movers as the dependent variable. The four control variables, i.e., year, location, product focus and firm size, were then entered (Model 1). We subsequently enter the measure for imitation of first movers by late movers with a high level of home-country similarity (Model 2).

Table 3 shows the results of the analyses. The data support hypothesis H3, which predicts that firms are more likely to imitate those first movers with whom they share a similar culture. Consistent with previous findings, the effect of year was also significant, suggesting that the cases of imitation had been increasing, which in turn led to more initiations of and increases in multi-market contact among the firms.

Table 3. The effects of first-mover imitation on MMC: The effect of home-country culture on imitations of first movers

\begin{tabular}{c|c|c|c}
\hline Variable & Model 1 & & Model 2 \\
\hline Year & $0.363^{*}$ & & $0.361^{*}$ \\
& $(0.141)$ & & $(0.122)$ \\
\hline Location & 20.320 & & 20.138 \\
& $(6.846)$ & & $(6.943)$ \\
\hline Product focus & -0.070 & & 0.017 \\
& $(0.152)$ & & $0.157)$ \\
\hline Firm Size & $0.355^{*}$ & $0.352^{*}$ \\
& $(0.150)$ & & $(0.148)$ \\
\hline Constant & -74.953 & -74.747 \\
& $(7.485)$ & & $(6.886)$ \\
\hline H3: More Likely Imitating First & & & $0.432^{*}$ \\
Movers with the Same Culture & & & $(0.162)$ \\
\hline
\end{tabular}

Note: ${ }^{*} \mathrm{p}<0.05 ;{ }^{* *} \mathrm{p}<0.01 ;^{* * *} \mathrm{p}<0.001$.

To test hypotheses $4 \mathrm{a}$ and $4 \mathrm{~b}$, we conducted hierarchical regression analyses because of the continuous 
dependent variable, i.e., deviation from industry norm. We first enter the four control variables, i.e., year, location, product focus and firm size (Model 1), followed by the independent variable, i.e., imitating first movers rather than late movers (Model 2).

Table 4 shows the results of this analysis, which support hypotheses $4 \mathrm{a}$ and $4 \mathrm{~b}$. Hypothesis $4 \mathrm{a}$ was supported by the results generated in step 2 (see part (a) in Table 4), which suggested that imitating first movers rather than later movers had a significant and negative effect on the dependent variable, i.e., deviation from the industry norm. Hypothesis $4 \mathrm{~b}$ was also supported by the results (see Part (B) in Table 4) --- imitating first movers or not had a significant and negative effect on the dependent variable, i.e., deviation from industry norm.

Table 4. How imitation of first-movers influences deviation from industry norm

(A) Hypothesis 4a

\begin{tabular}{c|c|c}
\hline & \multicolumn{2}{|c}{ Deviation } \\
\hline & Model 1 & Model 2 \\
\hline Control Variables & & $0.274^{* * *}$ \\
\hline Year & $0.276^{* * *}$ & -0.039 \\
\hline Location & 0.041 & 0.069 \\
\hline Product Focus & 0.070 & 0.052 \\
\hline Firm Size & 0.053 & $-0.122^{*}$ \\
\hline Independent Variables & & $36.050^{* * *}$ \\
\hline Imitation of First-mover Rather than & & 0.285 \\
\hline late-mover & & 0.081 \\
\hline Overall Model F & $48.095^{* * *}$ & 0.079 \\
\hline Multiple R & 0.285 & 0.137 \\
\hline R Square & 0.080 & \\
\hline Adjusted R Square & 0.079 & 0.137 \\
\hline Standard Error & & \\
\hline
\end{tabular}

(B) Hypothesis $4 \mathrm{~b}$

\begin{tabular}{c|c|c}
\hline & \multicolumn{2}{|c}{ Deviation } \\
\hline & Model 1 & Model 2 \\
\hline Control Variables & $0.276^{* * *}$ & $0.302^{* * *}$ \\
\hline Year & 0.041 & 0.068 \\
\hline Location & 0.070 & 0.064 \\
\hline Product Focus & 0.053 & 0.052 \\
\hline Firm Size & & $-0.216^{* * *}$ \\
\hline Imitating First-mover or not imitating & & $37.991^{* * *}$ \\
\hline Overall Model F & $37.370^{* * *}$ & 0.359 \\
\hline Multiple R & 0.291 & 0.129 \\
\hline R Square & 0.083 & 0.126 \\
\hline Adjusted R Square & 0.082 & 0.135 \\
\hline Standard Error & 0.139 & \\
\hline
\end{tabular}

Note: ${ }^{*} \mathrm{p}<0.05 ; * * \mathrm{p}<0.01 ; * * * \mathrm{p}<0.001$.

Using a similar approach, we also tested how deviation from the industry norm affects firm performance, the subject matter of hypotheses $5 \mathrm{a}$ and $5 \mathrm{~b}$. Table 5 presents the results of the analyses. Consistent with findings from past research (Chen and Hambrick, 1995), our data show that deviation has a significant and negative effect on the two dimensions of firm performance, i.e., labor productivity and firm profitability (ROA). These results support both hypotheses $5 \mathrm{a}$ and 5b, which are proposed based on institutional theory. 
Table 5. How deviation from industry norm influences firm performance

\begin{tabular}{|c|c|c|}
\hline \multirow[t]{2}{*}{ (5a) } & \multicolumn{2}{|c|}{ Labor Productivity } \\
\hline & Model 1 & Model 2 \\
\hline \multicolumn{3}{|l|}{ Control Variables } \\
\hline Year & $0.271^{* * *}$ & $0.280^{* * *}$ \\
\hline Location & 0.047 & -0.046 \\
\hline Product Focus & -0.102 & 0.080 \\
\hline Firm Size & $0.174^{*}$ & $0.170^{*}$ \\
\hline \multicolumn{3}{|l|}{ Independent Variables } \\
\hline Deviation from Industry Norm & & $-0.254^{* * *}$ \\
\hline Overall Model F & 3.683 & $18.012^{* * *}$ \\
\hline Multiple R & 0.088 & 0.268 \\
\hline R Square & 0.087 & 0.072 \\
\hline Adjusted R Square & 0.072 & 0.070 \\
\hline Standard Error & 0.602 & 0.594 \\
\hline
\end{tabular}

\begin{tabular}{|c|c|c|}
\hline \multirow[t]{2}{*}{$5 \mathrm{~b}$} & \multicolumn{2}{|c|}{ ROA } \\
\hline & Model 1 & Model 2 \\
\hline \multicolumn{3}{|l|}{ Control Variables } \\
\hline Year & $0.271^{* * *}$ & $0.264^{* * *}$ \\
\hline Location & 0.047 & $-0.12^{* * *}$ \\
\hline Product Focus & -0.102 & $-0.088^{* *}$ \\
\hline Firm Size & $0.174^{*}$ & $0.173^{*}$ \\
\hline \multicolumn{3}{|l|}{ Independent Variables } \\
\hline Deviation from Industry Norm & 3.683 & $-0.315^{* * *}$ \\
\hline Overall Model F & 0.088 & $48.34^{* * *}$ \\
\hline Multiple R & 0.087 & 0.405 \\
\hline R Square & 0.072 & 0.162 \\
\hline Adjusted R Square & 0.062 & 0.158 \\
\hline Standard Error & 0.072 & 0.135 \\
\hline
\end{tabular}

\section{$5 \quad$ Discussion and Implications}

This study has examined the effects of first-mover strategy on the performance of late movers by focusing on the issue of market diversification. Our data show that the effects of first-mover strategy on the performance of late movers can be observed through testing how late movers imitating the firstmovers. The first-mover strategy can attract more imitation by the late mover on such performance as market diversification, which can be seen as a direct effect of first-mover strategy on the performance of late movers. After leading to more imitation among late movers, the first-mover strategy can also influence the deviation from industry norm among the late movers, which in turn can affect the late movers' performance in terms of labor productivity and profitability.

The findings of our current study make several contributions. First, the findings from this study can motivate more research about the effects of first-mover strategy on the performance of late movers. So far the research on the effects has not been sufficient. As our data from this study suggest, while the first-mover strategy has several significant effects on the performance of first movers themselves, the same strategy can also influence the performance of late movers. From the perspective of game theory (Szidarovszky, Gershon and Duckstein, 1986), a first-mover can be seen as a leader, and a late-mover can be seen as a follower. In a multi-criteria and multi-stage game of strategic decision-making, it is of 
significance for both parties to understand or to predict correctly the measure and countermeasure strategies of the other party after the first strategic move by the leader or first mover. Because of this reason, the research of first-mover strategy should not limit itself to the performance of first-mover only; the effects of first-mover strategy on late movers should also be studied. In this sense, our current study makes a contribution to the research of first-mover strategy by motivating more research towards this direction.

In addition, the findings from our current study can assist subsequent studies of MNE behavior and strategies in emerging markets, where multinational firms from different cultures compete and engage in multi-market contact. With more and more multinational firms entering these new markets, the imitation of first-movers can become more and more interesting because it may become a major strategy for the firms to control uncertainties in their new environments.

Although this study has focused on the inter-organizational imitation of first movers among MNEs in emerging economies, the findings from this study should also be applicable to other economies of the world. This is because the same imitation of first-movers can take place in all economies and the imitation can be influenced by the same institutional factors, such as the similarity in terms of home culture. All these should be especially true for firms operating or competing in highly uncertain external environments.

\section{$6 \quad$ Limitation and Future Study}

Our current paper has obtained empirical evidence about the effects of first-mover strategy on late movers' performances, which help more comprehensive understanding of the consequences of the firstmover strategy. Although the results can contribute to the research of first-mover strategy, international business and strategic diversification, this paper still has some limitations that call for more effort of improvement in future research. In this section, we discuss these limitations.

On the one hand, the measurement of cultural similarity is simple. We understand that a homecountry culture consists of various dimensions, and it is better to measure each of the dimensions. However, there are some technical problems preventing us from testing every dimension of a homecountry culture. First, the dimensions of culture should not be considered equally important (cf. Hostede, 1980). Because different dimensions of culture are not equally important in terms of their effects on a certain organization behavior or performance, using their average score to measure cultural similarity here can be a problem. For example, the Collectivism of firm A could be similar to that firm B, but its value of Uncertainty Avoidance is more similar to that of firm $\mathrm{C}$. In this case, it would be difficult to decide which dyad of the firms, $\mathrm{A}$ and $\mathrm{C}$ or $\mathrm{A}$ and $\mathrm{B}$, should have a high level of similarity. Here there is no theory suggesting that Collectivism and Uncertainty Avoidance are equally important for the firm performances that we are studying here. The more dimensions of cultural values that we include in this study, the more significant this problem could be. The weighted average approach might be the solution to solve this problem. However, still, we don't have any theoretical guideline in the extant literature to decide the weight for each dimension of culture. Second, it might also be a problem if we use the Hostede data, which was collected many years ago, as a measurement of cultural similarity here. Considering recent research on cultural changes in many countries ( $\mathrm{Li}$, et al, 2012), we consider it questionable to measure cultural similarity using data collected decades ago. To address all these concerns, future study should develop better measurement of cultural similarity.

On the other hand, our current study tests only the effect of cultural similarity in China, which has a collectivistic cultural value in the society. It remains unclear whether the same cultural similarity should have a similar effect in societies with individualistic cultural values. Future studies should also consider this issue in societies with individualistic cultural values. Through doing this repeated testing, the external validities of our findings from this study can be understood better.

\section{References}

1. Baum, J.A.C., Li, S.X., Usher, J.M. "Making the next move: how experiential and vicarious learning shape the locations of chains' acquisitions, "Administrative Science Quarterly, 45: 766-801. 2000.

2. Chaffee, E. E. "Three models of strategy". Academy of Management Review, 10: 89-98. 1985. 
3. Chen, M., Hambrick, D.C. "Speed, stealth, and selective attack: how small firms differ from large firms in competitive behavior," Academy of Management Journal, 38: 453-482. 1995.

4. Cyert, R.M., March, J.G. A behavioral theory of the firm. Englewood Cliffs, NJ: Prentice-Hall. 1963.

5. DiMaggio, P., Powell, W.W. "The iron cage revisited: institutional isomorphism and collective rationality in organizational fields," American Sociological Review, 48: 147-160. 1983.

6. Frynas, J. K., Mellahi, K., Pigman, A. "First Mover Advantages in International Business and Firm-Specific Political Resources," Strategic Management Journal, 27(4): 321-345. 2006.

7. Glazer, A. "The advantages of being first," American Economic Review, 75: 473-80. 1985.

8. Granovetter, M. "Economic action and social structure: the problem of embeddedness," The American Journal of Sociology, 91: 481-510. 1985.

9. Gulati, R., N. Nohria., Zaheer, A. "Strategic Networks," Strategic Management Journal, 21: 203-215. 2000.

10.Haunschild, P.R., Miner, A.S. "Modes of interorganizational imitation: the effects of outcome salience and uncertainty," Administrative Science Quarterly, 42: 421-618. 1997.

11.Hitt, M.A., Hoskisson, R.E., Kim, H. "International diversification: effects on innovation and firm performance in product-diversified firms," Academy of Management Journal, 40: 767-798. 1997.

12.Jayachandran, S., Gimeno, J., Varadarajan, P.R. "Theory of multimarket competition: a synthesis and implications for marketing strategy," Journal of Marketing, 63: 49-66. 1999.

13.Korn, H.J., Baum, J.A.C. „Chance, imitative, and strategic antecedents to multimarket contact,” Academy of Management Journal, 42: 89-98. 1999.

14.Kunkel, S.W. The Impact of Strategy and Industry Structure on New Venture Performance. Unpublished doctoral dissertation, University of Georgia, Athens, GA. 1991.

15.Lambkin, M. "Order of entry and performance in new markets," Strategic Management Journal, 9: 127-40. 1988.

16.Li, S.X., Greenwood, R., "The effect of within-industry diversification on firm performance: synergy creation, multi-market contact and market structuration.," Strategic Management Journal, 25: 1131-1153. 2004.

17.Li, J., Lam, K., Sun, J., Liu ,S.X.Y. "Strategic human resource management, institutionalization, and employment modes--an empirical study in China," Strategic Management Journal, 29: 337-355. 2008.

18.Li, J.; Tan, Y.; Z. Cai; Zhu, H. \& Wang, X. "Regional differences in a national culture and their effects on leadership effectiveness, a tale of two neighboring Chinese cities," Journal of World Business. 2012.

19.Lieberman, M.B., Asaba, S. "Why do firms imitate each other?" Academy of Management Review, 31: 366-385. 2006.

20.McGrath, R.G., Chen, M., MacMillan, I.C. "Multimarket maneuvering in uncertain spheres of influence: resource diversion strategies," Academy of Management Review, 23: 724-740. 1998.

21.Patterson, W.G. "First-mover advantage: the opportunity curve," Journal of Management Studies, 30: 759-777. 1993.

22.Porter, M.E. Competitive Advantage: Creating and sustaining Superior Performance. The Free Press. 1985.

23.Vannoni, D. "Causes and effects of multimarket activity from theory to empirical analysis," Managerial and Decision Economics, 25(3): 163-174. 2004.

24.Robinson, W.T., Fornell, G. "Sources of market pioneer advantages in consumer goods industries," Journal of Market Research, 22: 305-17. 1985.

25.Schmalensee, R. "Product differentiation advantages of pioneering brands," American Economic Review, 72: 34965. 1982

26.Shipilov,A.V. "Firm Scope Experience, Historic Multimarket Contact with Partners, Centrality, and the Relationship between Structural Holes and Performance," Organization Science, 20(1): 85-106. 2009.

27.Scott, R. Institutions and Organizations. London: Sage. 2001.

28.Szidarovszky, F.; Gershon, M. and Duckstein, L. Techniques for multiobjective Decision-making in Systems Management. Elsevier, Amsterdam. 1986

29.Turner, D. "Matsushita to cut back overseas mobile phones production," Financial Times (Asia Edition), London (UK), Dec 10: 10. 2005.

30.Wang, Y. "Local insurance firms can compete," Business Weekly (in China Daily), North American Ed., Nov. 21: 3. 1999. 